\title{
Updating the Psoriatic Arthritis (PsA) Core Domain Set: A Report from the PsA Workshop at OMERACT 2016
}

\author{
Ana-Maria Orbai, Maarten de Wit, Philip J. Mease, Kristina Callis Duffin, Musaab Elmamoun, \\ William Tillett, Willemina Campbell, Oliver FitzGerald, Dafna D. Gladman, Niti Goel, \\ Laure Gossec, Pil Hoejgaard, Ying Ying Leung, Chris Lindsay, Vibeke Strand, \\ Désirée M. van der Heijde, Bev Shea, Robin Christensen, Laura Coates, Lihi Eder, \\ Neil McHugh, Umut Kalyoncu, Ingrid Steinkoenig, and Alexis Ogdie
}

ABSTRACT. Objective. To include the patient perspective in accordance with the Outcome Measures in Rheumatology (OMERACT) Filter 2.0 in the updated Psoriatic Arthritis (PsA) Core Domain Set for randomized controlled trials (RCT) and longitudinal observational studies (LOS).

Methods. At OMERACT 2016, research conducted to update the PsA Core Domain Set was presented and discussed in breakout groups. The updated PsA Core Domain Set was voted on and endorsed by OMERACT participants.

Results. We conducted a systematic literature review of domains measured in PsA RCT and LOS, and identified 24 domains. We conducted 24 focus groups with 130 patients from 7 countries representing 5 continents to identify patient domains. We achieved consensus through 2 rounds of separate surveys with 50 patients and 75 physicians, and a nominal group technique meeting with 12 patients and 12 physicians. We conducted a workshop and breakout groups at OMERACT 2016 in which findings were presented and discussed. The updated PsA Core Domain Set endorsed with 90\% agreement by OMERACT 2016 participants included musculoskeletal disease activity, skin disease activity, fatigue, pain, patient's global assessment, physical function, health-related quality of life, and systemic inflammation, which were recommended for all RCT and LOS. These were important, but not required in all RCT and LOS: economic cost, emotional well-being, participation, and structural damage. Independence, sleep, stiffness, and treatment burden were on the research agenda.

Conclusion. The updated PsA Core Domain Set was endorsed at OMERACT 2016. Next steps for the PsA working group include evaluation of PsA outcome measures and development of a PsA Core Outcome Measurement Set. (First Release February 15 2017; J Rheumatol 2017;44:1522-8; doi:10.3899/jrheum.160904)

Key Indexing Terms: PSORIATIC ARTHRITIS

From the Division of Rheumatology, Johns Hopkins University School of Medicine, Baltimore, Maryland; Rheumatology Research, Swedish Medical Center and University of Washington School of Medicine, Seattle, Washington; Department of Dermatology, University of Utah, Salt Lake City, Utah; Quintiles, Duke University School of Medicine, Durham, North Carolina; Division of Immunology, Stanford University, Palo Alto, California; Cleveland Clinic, Cleveland, Ohio; University of Pennsylvania, Philadelphia, Pennsylvania, USA; VU Medical Centre, Amsterdam; Department of Rheumatology, Leiden University Medical Center, Leiden, the Netherlands; Department of Rheumatology, St. Vincent's University Hospital, and Conway Institute for Biomolecular Research, University College Dublin, Dublin, Ireland; Royal National Hospital for Rheumatic Diseases; Royal National Hospital for Rheumatic Diseases, Bath; Leeds Institute of Rheumatic and Musculoskeletal Medicine, University of Leeds; Leeds Musculoskeletal Biomedical Research Unit, Leeds Teaching Hospitals UK National Health Service (NHS) Trust, Leeds, UK; Toronto Western Hospital; University of Toronto; Krembil Research Institute; Psoriatic Arthritis Program, University Health Network; Women's College Research Institute, Women's College Hospital, University of Toronto, Toronto; Ottawa Hospital Research Institute, School of Epidemiology, Public Health and Preventative Medicine, University of Ottawa, Ottawa, Ontario, Canada; Sorbonne Universités, UPMC Univ Paris 06, Institut Pierre Louis d'Epidémiologie et de Santé Publique, GRC-UPMC 08 (EEMOIS); AP-HP, Pitié Salpêtrière Hospital, Department of Rheumatology, Paris, France; The Parker Institute,
Bispebjerg and Frederiksberg Hospital, Frederiksberg, Denmark; Department of Rheumatology and Immunology, Singapore General Hospital, Singapore; Department of Internal Medicine, Division of Rheumatology, Hacettepe University, Ankara, Turkey.

AMO was supported in part by a Scientist Development Award from the Rheumatology Research Foundation and the Johns Hopkins Arthritis Center Discovery Fund. AO was supported by research grant K23 AR063764 from the US National Institute of Arthritis and Musculoskeletal and Skin Diseases (NIAMS). This work was supported in part by research grant P30-AR053503 (RDRCC Human Subjects Research Core) from NIAMS and the Camille J. Morgan Arthritis Research and Education Fund. The international focus group study was supported by research grants from Celgene and Janssen. The nominal group technique meeting was supported by research grants from AbbVie, Celgene, and Pfizer. The UK focus group study was funded by the National Institute for Health Research (Programme Grants for Applied Research, Early detection to improve outcome in patients with undiagnosed psoriatic arthritis, RP-PG-1212-20007). Attendance of working group fellows and patient research partners to the Outcome Measures in Rheumatology (OMERACT) conference was supported with workshop funds from Group for Research and Assessment of Psoriasis and Psoriatic Arthritis and OMERACT.

A.M. Orbai, MD, MHS, Division of Rheumatology, Johns Hopkins University School of Medicine; M. de Wit, PhD, Patient Research Partner, 
VU Medical Centre; P.J. Mease, MD, Rheumatology Research, Swedish Medical Center, and University of Washington School of Medicine;

K. Callis Duffin, MD, Department of Dermatology, University of Utah; M. Elmamoun, MBBS, MRCPI, Department of Rheumatology, St. Vincent's University Hospital, and Conway Institute for Biomolecular Research, University College Dublin; W. Tillett, BSc, MB ChB, PhD, MRCP, Royal National Hospital for Rheumatic Diseases; W. Campbell, BEd LLB, Patient Research Partner, Toronto Western Hospital; O. FitzGerald, MD, FRCPI, FRCP(UK), Newman Clinical Research Professor, Department of Rheumatology, St. Vincent's University Hospital, and Conway Institute for Biomolecular Research, University College Dublin; D.D. Gladman, MD, FRCPC, Professor of Medicine, University of Toronto, and Senior Scientist, Krembil Research Institute, and Director, Psoriatic Arthritis Program, University Health Network; N. Goel, MD, Patient Research Partner, Quintiles, Duke University School of Medicine; L. Gossec, MD PhD, Sorbonne Universités, UPMC Univ Paris 06, Institut Pierre Louis d'Epidémiologie et de Santé Publique, GRC-UPMC 08 (EEMOIS), and AP-HP, Pitié Salpêtrière Hospital, Department of Rheumatology; P. Hoejgaard, MD, The Parker Institute, Bispebjerg and Frederiksberg Hospital; Y.Y. Leung, MD, PhD, Department of Rheumatology and Immunology, Singapore General Hospital; C.A. Lindsay, PharmD, Patient Research Partner; V. Strand, MD, Division of Immunology, Stanford University; D.M. van der Heijde, $M D, P h D$, Department of Rheumatology, Leiden University Medical Center; B. Shea, MSc, PhD, Senior Methodologist, Ottawa Hospital Research Institute, Adjunct Professor, School of Epidemiology, Public Health and Preventative Medicine, Faculty of Medicine, University of Ottawa; R. Christensen, BSc, MSc, PhD, Head of Unit, Professor of Clinical Epidemiology, Musculoskeletal Statistics Unit, The Parker Institute, Bispebjerg and Frederiksberg Hospital; L. Coates, $M B C h B, P h D$, Leeds Institute of Rheumatic and Musculoskeletal Medicine, University of Leeds, and Leeds Musculoskeletal Biomedical Research Unit, Leeds Teaching Hospitals NHS Trust; L. Eder, MD, PhD, Women's College Research Institute, Women's College Hospital, University of Toronto; N. McHugh, MBChB, MD, FRCP, FRCPath, Royal National Hospital for Rheumatic Diseases; U. Kalyoncu, MD, Department of Internal Medicine, Division of Rheumatology, Hacettepe University; I. Steinkoenig, BA, Patient Research Partner, Cleveland Clinic; A. Ogdie, MD, MSCE, University of Pennsylvania.

Address correspondence to Dr. A.M. Orbai, Johns Hopkins Arthritis Center, 5501 Hopkins Bayview Circle, AAC-1B, Baltimore, Maryland 21224,USA.E-mail: aorbai1@jhmi.edu

Full Release Article. For details see Reprints and Permissions at jrheum.org

Accepted for publication December 20, 2016.

The updated 2016 Psoriatic Arthritis (PsA) Core Domain Set contains the following revised or new domains compared with the 2006 core set:

- Musculoskeletal (MSK) disease activity (revised to include peripheral joints, dactylitis, enthesitis, and spine symptoms)

- Skin activity (revised to include skin and nails)

- Fatigue

- Systemic inflammation

- Participation, emotional well-being, structural damage, and economic cost are designated important and not required in all clinical trials.

The purpose of disease core sets is to standardize measurement and reporting of outcomes in randomized controlled trials (RCT) and longitudinal observational studies (LOS). Implementation and reporting of disease core sets in RCT is key to generating high-quality evidence to support useful treatment recommendations ${ }^{1}$. Outcome Measures in Rheumatology (OMERACT) pioneered disease core set development and refined its methodology based on evidence $^{2,3,4}$. In 2014, OMERACT presented and published Filter 2.0, outlining a methodologically rigorous process for defining core domain sets ${ }^{5}$ based on early inclusion of the views of all involved (especially patients) and iterative, evidence-driven consensus. At the OMERACT 2014 conference, participants recognized the need to update the PsA Core Domain Set based on the new OMERACT filter and, integral to this process, to incorporate the voice of patients and rapidly developing scientific knowledge about the disease and the measurement of PsA ${ }^{6,7}$. OMERACT 2014 attendees (including researchers, patient partners, and clinicians) voted to update the PsA core domain set (100\% voted "yes") and additionally voted to include fatigue (72\%) and dactylitis $(70 \%)$ in the core $\operatorname{set}^{8}$.

Since the OMERACT 2014 meeting, the Group for Research and Assessment of Psoriasis and Psoriatic Arthritis (GRAPPA)-OMERACT PsA working group conducted research projects ${ }^{9}$ to identify domains important to patients and physicians for the PsA Core Domain Set update. Our paper summarizes the results presented at the OMERACT 2016 PsA workshop and breakout group discussions, and the subsequent endorsement of the updated PsA Core Domain Set.

\section{Summary of Research Conducted in Preparation for OMERACT 2016}

The PsA working group conducted the following research projects: (1) a systematic literature review (SLR) in PubMed and EMBASE to identify domains measured in PsA RCT, LOS, and registries; (2) international focus groups with patients with PsA to identify domains; (3) international patient and physician surveys; and (4) a consensus meeting held March 12, 2016, in Jersey City, New Jersey, USA with patients and physicians using the nominal group technique (NGT) to draft a PsA Core Domain Set. Detailed methods and results are presented in separate manuscripts $9,10,11$.

Studies were approved by the Johns Hopkins University Institutional Review Board (IRB), Baltimore, Maryland, USA (IRB00093948 and NA_00066663) and the National Research Ethics Service Committee North West - Haydock, UK (REC reference: 15/NW/0609). The online survey study was accorded exempt status at the University of Pennsylvania IRB, Philadelphia, Pennsylvania, USA.

The SLR has been published and showed the measurement of the complete 2006 PsA Core Domain Set increased from being performed in $24 \%$ of RCT (from 2005 to 2010 ) to $59 \%$ of RCT (from 2010 to 2015$)^{10,11}$. Twenty-four domains were identified from the SLR, with 18 measured in addition to the core set (Figure 1). The changes over time are likely related to dissemination of the PsA Core Set, recognition of the importance of fatigue, productivity, and other aspects of life effect for patients ${ }^{8,12,13,14}$, and availability of outcome measures for domains such as dactylitis ${ }^{15}$.

Qualitative research was conducted to identify domains

Personal non-commercial use only. The Journal of Rheumatology Copyright (C) 2017. All rights reserved 


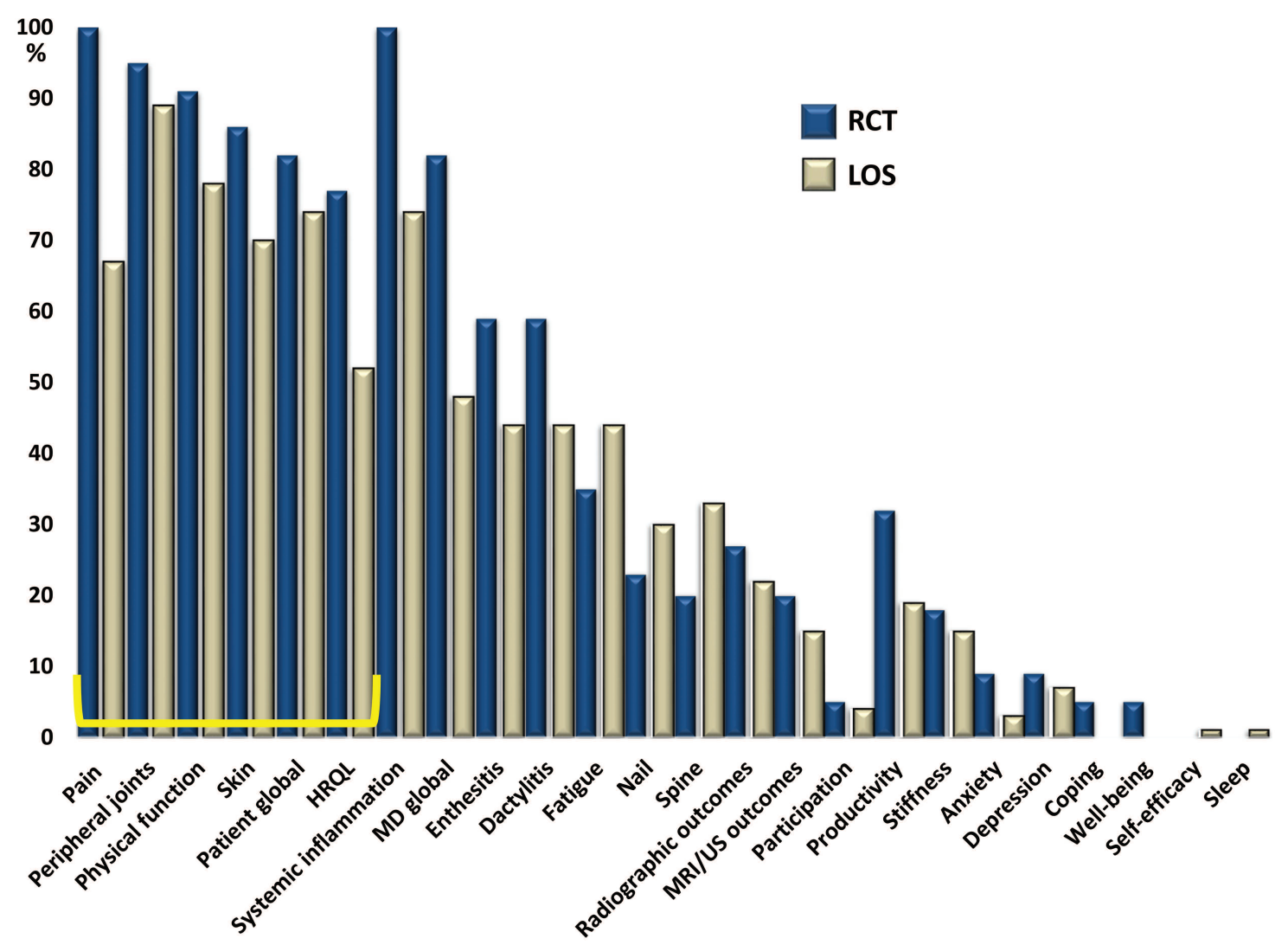

Figure 1. Domains are shown on the $\mathrm{X}$ axis with proportion of studies measuring each domain on the $\mathrm{Y}$ axis. The yellow mark designates 2006 PsA core domains. RCT: randomized controlled trials; LOS: longitudinal observational studies; HRQL: health-related quality of life; MD: physician; MRI: magnetic resonance imaging; US: ultrasound.

directly from patients to include their perspective at the inception of the process ${ }^{16}$. Two focus group studies were conducted: 1 international (16 focus groups with 89 patients in total in Australia, Brazil, France, the Netherlands, Singapore, and the United States) and 1 multicenter study in the United Kingdom ( 8 focus groups with 41 patients). Qualitative data analysis of each study identified patient domains. Across both studies there were 34 unique patient domains.

The 24 domains from the SLR and 34 domains from international focus groups were then combined into a list of 39 unique domains. Patients $(n=50)$ recruited from rheumatology clinics and patient organizations and physicians $(n=75)$ recruited through GRAPPA rated domains through electronic surveys running in parallel. Results were discussed at the NGT consensus meeting held March 12, 2016, with 12 patients and 12 physicians. The NGT method allowed items to be prioritized, ensuring the inclusion of all participants' opinions ${ }^{17}$.

At the end of the consensus meeting, a draft core domain set was agreed upon and included 10 domains: MSK disease activity (peripheral joints, enthesitis, dactylitis, and spine symptoms), skin disease activity (skin and nails), pain, patient's global assessment (PtGA; patient-reported disease-related health status), physical function, participation, emotional well-being, fatigue, systemic inflammation, and structural damage (to be measured at least once during a new drug development program for PsA). A domain considered important but not required in all RCT and LOS was economic cost (societal financial effect not otherwise identified by participation and work/employment domains). The NGT core domain set was then rated in a second electronic survey completed in parallel by patients and physicians. Based on results from the second round of surveys, the draft core domain set included these 9: MSK disease activity, skin disease activity, pain, PtGA, physical function, participation, fatigue, systemic inflammation, and structural damage (to be measured at least once during a new drug development program for PsA; Table 1).

Patients were involved at all levels as research participants, patient researchers (conducting focus groups and analyzing data), or patient research partners (PRP; assisting in the high-level conduct of the research) in each of the work streams, as presented in Table 2. One PRP was a member of the Steering Committee for the working group.

\section{Working Group Meeting at OMERACT 2016}

A working group meeting was held at OMERACT prior to 
Table 1. Domains in the 2006 PsA Core Domain Set and candidate domains for the updated core set.

\begin{tabular}{|c|c|c|c|}
\hline $\begin{array}{l}\text { OMERACT } 2006 \\
\text { PsA Core } \\
\text { Domain Set }\end{array}$ & $\begin{array}{l}\text { OMERACT } 2014 \\
\text { Voted }(\geq 70 \%) \\
\text { Inclusion in } \\
\text { the Core Set }\end{array}$ & $\begin{array}{l}\text { Draft Core Domain Set } \\
\text { at the End of the NGT } \\
\text { Meeting } 2016\end{array}$ & $\begin{array}{l}\text { Draft Core Set after } \\
\text { the Second Patient and } \\
\text { Physician Survey* }\end{array}$ \\
\hline $\begin{array}{l}\text { Peripheral joint activity } \\
\text { Skin activity } \\
\text { Pain } \\
\text { Patient global } \\
\text { Physical function } \\
\text { HRQOL }\end{array}$ & Dactylitis & $\begin{array}{c}\text { MSK disease activity } \\
\text { Skin disease activity } \\
\text { Pain } \\
\text { PtGA } \\
\text { Physical function } \\
\text { Participation } \\
\text { Emotional well-being } \\
\text { Fatigue } \\
\text { Systemic inflammation } \\
\text { Structural damage } * *\end{array}$ & $\begin{array}{c}\text { MSK disease activity } \\
\text { Skin disease activity } \\
\text { Pain } \\
\text { PtGA } \\
\text { Physical function } \\
\text { Participation } \\
\text { Fatigue } \\
\text { Systemic inflammation } \\
\text { Structural damage } * *\end{array}$ \\
\hline
\end{tabular}

* During the second survey, patients and physicians rated the importance of domains proposed after the NGT meeting - emotional well-being was moved out of the core because less than $70 \%$ of either physician or patient respondents rated it as at least 8 on a scale from $0-10 . * *$ Structural damage was recommended for assessment at least once during the development of a new drug for PsA. PsA: psoriatic arthritis; OMERACT: Outcome Measures in Rheumatology; NGT: nominal group technique; HRQOL: health-related quality of life; MSK: musculoskeletal; PtGA: patient's global assessment.

the PsA Workshop for final review of the workshop presentation, breakout group organization, and voting questions. At this meeting, these decisions were made regarding the core domain set to be presented at the workshop:

(1) Structural damage was important, but not required in all RCT and LOS. This was congruent with the NGT meeting in which structural damage was recommended to be measured once during the development of a new therapeutic agent for PsA, but not required in all RCT.

(2) Health-related quality of life (HRQOL) remained a core domain required in all RCT and LOS based on its presence in the 2006 Core Domain Set.

(3) The group decided to hold 2 separate votes for participation: first, for inclusion in the core domain set (required in all RCT and LOS) and second (if first not agreed by $70 \%$ ), for inclusion in the middle circle (important, but not required in all RCT and LOS). Work/employment (included in participation) was rated high in the first survey by both patients and physicians, and participation was in the preliminary core set after the NGT meeting as well as rated high by patients in the second survey. However, because of feasibility concerns and overlap of participation with the broader concept of HRQOL, we anticipated both may not be accepted in the core set (thus the decision to hold 2 votes).

(4) Because of the importance of emotional well-being for patients, both in the NGT meeting and also at this working group meeting, the group similarly decided to first vote for inclusion of emotional well-being in the core set and second

Table 2. Patients involved in the PsA Core Domain Set update. Values are $\mathrm{n}$.

\begin{tabular}{|c|c|c|c|c|}
\hline Country & $\begin{array}{c}\text { International } \\
\text { Patient Focus } \\
\text { Group Participants }\end{array}$ & $\begin{array}{l}\text { Qualitative Data } \\
\text { Analysis (Patient } \\
\text { Researchers, PRP) }\end{array}$ & $\begin{array}{c}\text { Survey } \\
\text { Participants }\end{array}$ & $\begin{array}{c}\text { Nominal Group } \\
\text { Technique Patient } \\
\text { Participants and PRP }\end{array}$ \\
\hline Australia & 7 & & & \\
\hline Brazil & 12 & & 1 & 1 \\
\hline Canada & & 1 & 1 & 2 \\
\hline France & 12 & & 4 & \\
\hline Hong Kong & & & 1 & \\
\hline Ireland & & & 9 & 1 \\
\hline Italy & & & 1 & \\
\hline Netherlands & 17 & 2 & 1 & 1 \\
\hline Norway & & & 1 & 1 \\
\hline Romania & & & 1 & \\
\hline Singapore & 13 & & 8 & \\
\hline Spain & & & 1 & \\
\hline UK & 41 & 2 & 3 & 1 \\
\hline USA & 27 & 1 & 18 & 4 \\
\hline Total & 129 & 6 & 50 & 12 \\
\hline
\end{tabular}

PsA: psoriatic arthritis; PRP: patient research partners. 
(if first not agreed by 70\%) to vote for inclusion in the middle circle. The group also agreed upon the final list of voting questions for the conclusion of the workshop.

\section{OMERACT 2016 PsA Workshop}

The PsA workshop began with the presentation of results, continued with 8 breakout group discussions running in parallel, followed by reports from each breakout group, and concluded with voting. Results from research conducted in preparation for OMERACT were presented to workshop participants as above (Table 1).

Breakout group discussions were facilitated by 2 people ( 1 moderator and 1 reporter), both of whom were either a member of the working group or experienced PsA or psoriasis researchers. The 4 PsA working group PRP were either a group moderator or reporter. All breakout groups discussed each new or updated domain: participation, systemic inflammation, MSK disease activity, skin activity, emotional well-being, and structural damage. Fatigue had been voted for inclusion in the core domain set by $72 \%$ of the participants at the OMERACT 2014 conference ${ }^{8}$ and was not discussed again. For each domain breakout group, participants were asked to provide arguments supporting inclusion in the core domain set as well as perceived challenges. Throughout the process of developing the core set and also in the breakout groups, discussion of how to best measure a particular domain was discouraged because instruments were not considered relevant at this stage to the decision on which domains to include. A summary of breakout group discussions is presented in Supplementary Table 1 (available with the online version of this article).

Following the breakout group reporting in the plenary, OMERACT participants voted for individual domains and this concluded the workshop (Table 3 ). The only modification to the preliminary core set was moving participation to the middle circle (important, but not required in all RCT and LOS).

\section{OMERACT 2016 Final Plenary}

At the OMERACT plenary, the final PsA 2016 Core Domain Set was proposed for endorsement and achieved consensus with a $90 \%$ vote from 130 participants at the conference. The updated 2016 PsA Core Domain Set includes the following outcomes recommended for assessment in all RCT and LOS (inner core): MSK disease activity, skin disease activity, fatigue, pain, PtGA, physical function, HRQOL, and systemic inflammation. The following outcomes (middle circle) are important, but not required in all RCT/LOS: economic cost, emotional well-being, participation, and structural damage. Outcomes that need to be studied further because of their importance for people with PsA include independence, sleep, stiffness, and treatment burden (Figure 2$)^{11}$.

Contextual factors for PsA are another important area that needs further study. Adverse events are measured in every RCT and are part of the OMERACT outcome framework. The updated 2016 PsA Core Domain Set addresses all areas of the OMERACT Filter 2.0 framework (Figure 3$)^{5}$.

\section{DISCUSSION}

PsA is a heterogeneous disease with tremendous effect on patients' lives. At OMERACT 2014, the GRAPPA-OMERACT PsA working group committed to updating the 2006 PsA Core Domain set to incorporate the input of people living with PsA and advances in the field. Candidate domains for the updated PsA Core Domain Set were obtained directly from patients through international focus groups and an SLR of outcomes measured in PsA RCT, LOS, and registries. During the surveys and consensus meeting with patients and physicians, each domain presented for rating or discussion was accompanied by a clear definition based on focus group patient participants' descriptions and reviewed by the working group, including PRP. We adopted this method to maximize understanding for all participants and to minimize subjective interpretations during the surveys and the consensus meeting.

The concept of MSK disease activity, which encompasses peripheral joints, enthesitis, dactylitis, and spine symptoms, had been suggested initially in breakout groups at OMERACT $2014^{8}$ out of concerns for parsimony in the core set. This comprehensive definition for MSK disease activity was fully supported at the consensus meeting with patients and physicians and endorsed with majority vote at OMERACT 2016.

Discussion at OMERACT 2016 focused particularly on the inclusion of participation and emotional well-being.

Table 3. Voting results at the conclusion of the PsA workshop. Values are \%.

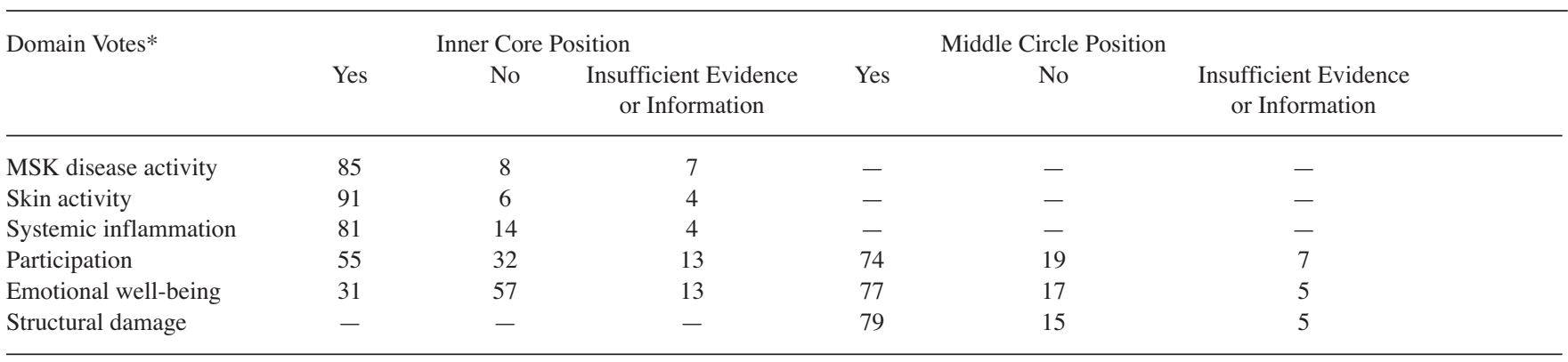

\footnotetext{
* The number of OMERACT participants who voted for each question ranged from 132 to 138. PsA: psoriatic arthritis; MSK: musculoskeletal
} 


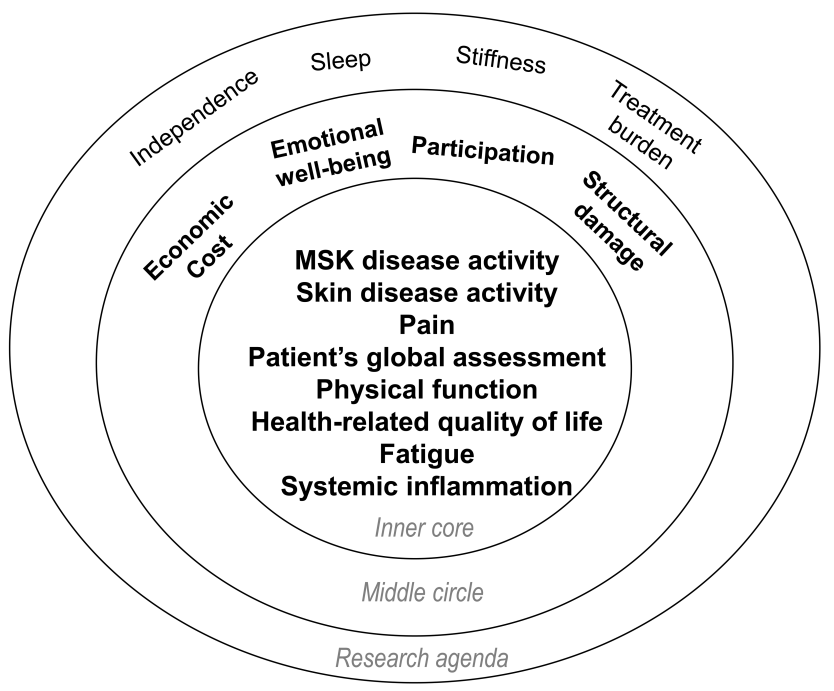

Figure 2. Updated 2016 PsA Core Domain Set. MSK disease activity includes peripheral joints, enthesitis, dactylitis, and spine symptoms. Skin activity includes skin and nails. PtGA is defined as patient-reported disease-related health status. The inner circle includes domains recommended for measurement in every RCT and LOS. The middle circle includes domains that are important, but not required in every RCT and LOS. The outer circle contains domains that may be important, but need further study. PsA: psoriatic arthritis; MSK: musculoskeletal; PtGA: patient's global assessment; RCT: randomized controlled trial; LOS: longitudinal observational studies. Reproduced with permission from Orbai, et al. Ann Rheum Dis 2016 Sep 9 (E-pub ahead of print).
Participation (encompassing work and/or employment within and outside the home, leisure activities, social activities, and family roles) was defined congruent with the International Classification of Functioning, Disability and Health definition, which is "involvement in a life situation" and distinct from activity, which implies "the execution of a task or action" 18 . Ability to perform work (both paid and unpaid) is an important outcome to patients and ranked highly in surveys with patients conducted by our working group and also in the European League Against Rheumatism-led Psoriatic Arthritis Impact of Disease (PsAID) study ${ }^{12}$. Estimates of unemployment and work disability range from $20 \%-50 \%$ and $16 \%-39 \%$, respectively, in clinical trials and cohort studies ${ }^{19}$, and appropriate therapy can improve aspects of participation ${ }^{20}$. Therefore, participation has face validity, and optimal measurement needs to be studied further.

Emotional well-being was defined as "feeling good about oneself" and may include additional domains such as depressive mood, anxiety, embarrassment, self-worth, frustration, and stress. During the NGT meeting, emotional well-being was highly relevant to the management of PsA for patient participants. Previous studies suggested that $20 \%$ of patients with PsA had depression and 1 study found that $37 \%$ had anxiety ${ }^{21}$. The best way of measuring emotional well-being in patients with PsA has not been investigated. The PsAID includes items on depression, anxiety, and embarrassment, and the Medical Outcomes Study Short Form-36 includes "mental health," "role emotional," "vitality," and also "social functioning" domains ${ }^{22}$. Following discussions

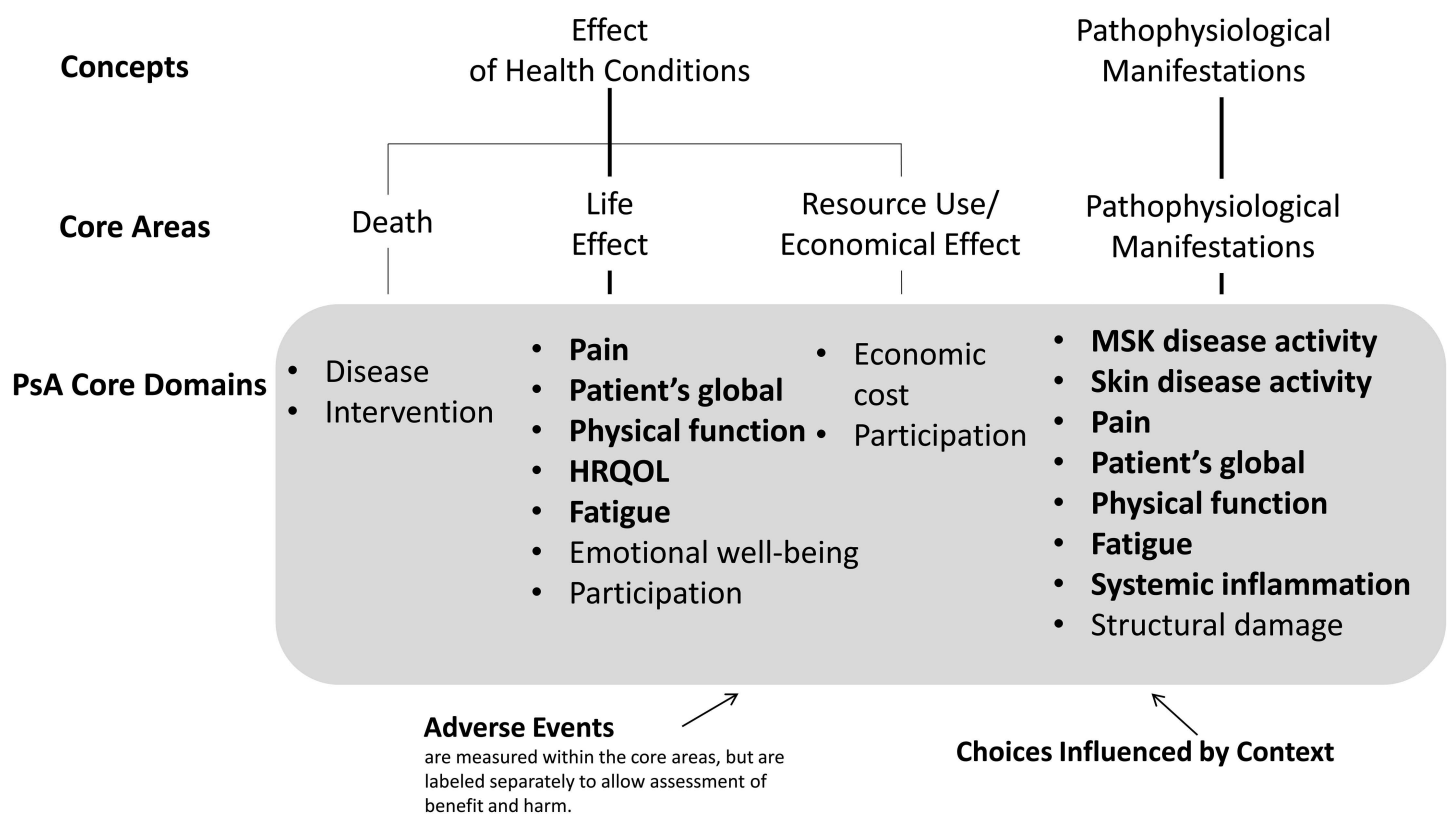

Figure 3. Updated PsA Core Domain Set and corresponding OMERACT core areas. Domains in bold face are in the core set (to be measured in all RCT), and domains in plain font are in the middle circle (highly recommended, but not mandatory). PsA: psoriatic arthritis; OMERACT: Outcome Measures in Rheumatology; RCT: randomized controlled trial; HRQOL: health-related quality of life; MSK: musculoskeletal. From Boers M, et al. J Clin Epidemiol 2014;67:745-53; adapted with permission.

Personal non-commercial use only. The Journal of Rheumatology Copyright @ 2017 . All rights reserved. 
at OMERACT 2016, and in line with the second survey with patients and physicians, it became clear that additional research may be needed before emotional well-being might become an inner core element.

An aspect discussed for both participation and emotional well-being was conceptual overlap with HRQOL. Concomitant measurement of all these concepts may be redundant and demanding on responders. Another consideration is that patient participants in focus groups described specific areas of PsA life effect: participation, fatigue, and emotional well-being. There was discussion to replace the generic construct of HRQOL with these explicit domains that are patient-relevant. This is an important area for future research in PsA.

Next steps include investigation of instruments available to measure the core domain set. We are beginning this process with an SLR of instruments for each core domain. We will investigate psychometric properties of available instruments such as face and content validity (including match with the domain of interest) and feasibility as a part of the recently described OMERACT decision-making process for selection of outcome measures or "the eyeball test" 23,24 . Focus groups will take into account patients' impressions of the instruments. We will simultaneously examine instrument construct validity and responsiveness in RCT datasets and LOS currently in progress. These work streams will inform the development of a PsA Core Outcome Measurement Set.

Additionally, the research agenda included items of importance to patients: independence, sleep, stiffness, and treatment burden. These domains need further study of their contribution to PsA assessment.

The updated PsA Core Domain Set incorporates patient input, scientific knowledge of pathophysiologic manifestations and measurement of disease in PsA, and the broad life effect of PsA. Next steps include development of a PsA Core Outcome Measurement Set for RCT and LOS.

\section{ONLINE SUPPLEMENT}

Supplementary material accompanies the online version of this article.

\section{REFERENCES}

1. Tunis SR, Clarke M, Gorst SL, Gargon E, Blazeby JM, Altman DG, et al. Improving the relevance and consistency of outcomes in comparative effectiveness research. J Comp Eff Res 2016;5:193-205.

2. Boers M, Brooks P, Strand CV, Tugwell P. The OMERACT filter for Outcome Measures in Rheumatology. J Rheumatol 1998;25:198-9.

3. Boers M, Kirwan J, Tugwell P, Beaton D, Bingham CO 3rd, Conaghan PG, et al. The OMERACT Handbook. OMERACT; 2014.

4. Gladman DD, Mease PJ, Strand V, Healy P, Helliwell PS, Fitzgerald $\mathrm{O}$, et al. Consensus on a core set of domains for psoriatic arthritis. J Rheumatol 2007;34:1167-70

5. Boers M, Kirwan JR, Wells G, Beaton D, Gossec L, d'Agostino MA, et al. Developing core outcome measurement sets for clinical trials: OMERACT filter 2.0. J Clin Epidemiol 2014;67:745-53.

6. Coates LC, Kavanaugh A, Mease PJ, Soriano ER, Laura Acosta-Felquer M, Armstrong AW, et al. Group for Research and Assessment of Psoriasis and Psoriatic Arthritis 2015 Treatment Recommendations for Psoriatic Arthritis. Arthritis Rheumatol 2016;68:1060-71.
7. Kirwan JR, de Wit MP, Bingham CO 3rd, Leong A, Richards P, Tugwell P, et al; Outcome Measures in Rheumatology Executive Committee. Commentary: Patients as partners: building on the experience of outcome measures in rheumatology. Arthritis Rheumatol 2016;68:1334-6.

8. Tillett W, Eder L, Goel N, De Wit M, Gladman DD, FitzGerald O, et al. Enhanced patient involvement and the need to revise the core set - report from the Psoriatic Arthritis Working Group at OMERACT 2014. J Rheumatol 2015;42:2198-203.

9. Orbai AM, Mease PJ, de Wit M, Kalyoncu U, Campbell W, Tillett W, et al. Report of the GRAPPA-OMERACT Psoriatic Arthritis Working Group from the GRAPPA 2015 Annual Meeting. J Rheumatol 2016;43:965-9.

10. Kalyoncu U, Ogdie A, Campbell W, Bingham CO 3rd, de Wit M, Gladman DD, et al. Systematic literature review of domains assessed in psoriatic arthritis to inform the update of the psoriatic arthritis core domain set. RMD Open 2016;2:e00217.

11. Orbai AM, de Wit M, Mease P, Shea JA, Gossec L, Leung YY, et al. International patient and physician consensus on a psoriatic arthritis core outcome set for clinical trials. Ann Rheum Dis 2016 Sep 9 (E-pub ahead of print).

12. Palominos PE, Gaujoux-Viala C, Fautrel B, Dougados M, Gossec L. Clinical outcomes in psoriatic arthritis: a systematic literature review. Arthritis Care Res 2012;64:397-406.

13. Gossec L, de Wit M, Kiltz U, Braun J, Kalyoncu U, Scrivo R, et al; EULAR PsAID Taskforce. A patient-derived and patient-reported outcome measure for assessing psoriatic arthritis: elaboration and preliminary validation of the Psoriatic Arthritis Impact of Disease (PsAID) questionnaire, a 13-country EULAR initiative. Ann Rheum Dis 2014;73:1012-9.

14. Walsh JA, McFadden ML, Morgan MD, Sawitzke AD, Duffin KC, Krueger GG, et al. Work productivity loss and fatigue in psoriatic arthritis. J Rheumatol 2014;41:1670-4.

15. Gudu T, Etcheto A, de Wit M, Heiberg T, Maccarone M, Balanescu A, et al. Fatigue in psoriatic arthritis - a cross-sectional study of 246 patients from 13 countries. Joint Bone Spine 2016;83:439-43.

16. Healy PJ, Helliwell PS. Measuring dactylitis in clinical trials: which is the best instrument to use? J Rheumatol 2007;34:1302-6.

17. Keeley T, Williamson P, Callery P, Jones LL, Mathers J, Jones J, et al. The use of qualitative methods to inform Delphi surveys in core outcome set development. Trials 2016;17:230.

18. Van de Ven AH, Delbecq AL. The nominal group as a research instrument for exploratory health studies. Am J Public Health 1972;62:337-42.

19. World Health Organization. Towards a common language for functioning, disability and health ICF. Geneva: World Health Organization; 2002:9-10.

20. Tillett W, de-Vries C, McHugh NJ. Work disability in psoriatic arthritis: a systematic review. Rheumatology 2012;51:275-83.

21. Kavanaugh A, Gladman D, van der Heijde D, Purcaru O, Mease PJ. Clinical responses in joint and skin outcomes and patient-reported outcomes are associated with increased productivity in the workplace and at home in psoriatic arthritis patients treated with certolizumab pegol. Value Health 2015;18:A654.

22. Ogdie A, Schwartzman S, Husni ME. Recognizing and managing comorbidities in psoriatic arthritis. Curr Opin Rheumatol 2015;27:118-26.

23. Orbai AM, Ogdie A. Patient-reported outcomes in psoriatic arthritis. Rheum Dis Clin North Am 2016;42:265-83.

24. Beaton DE, Terwee CB, Singh JA, Hawker GA, Patrick DL, Burke $\mathrm{LB}$, et al. A call for evidence-based decision making when selecting outcome measurement instruments for summary of findings tables in systematic reviews: results from an OMERACT Working Group. J Rheumatol 2015;42:1954-61. 


\section{Correction}

Updating the Psoriatic Arthritis (PsA) Core Domain Set: A Report from the PsA Workshop at OMERACT 2016*

Orbai AM, de Wit M, Mease PJ, Callis Duffin K, Elmamoun $\mathrm{M}$, Tillett W, et al. Updating the psoriatic arthritis (PsA) core domain set: a report from the PsA workshop at OMERACT 2016. J Rheumatol 2017; doi:10.3899/jrheum.160904. In Table 2, some data are incorrect in the rows for France, USA, and Total. In the first data column, the number for France should be 12 , the number for USA should be 27 , and the number for the Total should be 129 .

*This correction is to the First Release version only, published online February 1, 2017.

doi:10.3899/jrheum.160904.C1 